\title{
Effects of melatonin implants in spring on testicular regression and moulting in adult male raccoon dogs (Nyctereutes procynoides)
}

\author{
Y. Xiao ${ }^{1}$, M. Forsberg ${ }^{2}$, J. T. Laitinen ${ }^{3}$ and M. Valtonen ${ }^{1 *}$ \\ ${ }^{1}$ Department of Applied Zoology and Veterinary Medicine and ${ }^{3}$ Department of Physiology, \\ University of Kuopio, PO Box 1627, SF-70211 Kuopio, Finland; and ${ }^{2}$ Department of Clinical Chemistry, \\ College of Veterinary Medicine, Swedish University of Agricultural Sciences, PO Box 7038, \\ S-750 07 Uppsala, Sweden
}

\begin{abstract}
Six male raccoon dogs were treated with constant-release implants of melatonin on 29 March, when the animals still had mature spermatozoa and a winter coat. Six untreated animals served as controls. High serum concentrations of melatonin were found in the treated animals throughout the study period (182.2 and $38.5 \mathrm{pg} \mathrm{ml}^{-1}$ in April and August, respectively). The high serum concentrations of prolactin in April and May (18.9 and $15.7 \mathrm{ng} \mathrm{ml}^{-1}$, respectively) in the controls were not seen in the treated animals. Testicular regression, judged by width of the testis and stage of spermatogenesis, was slowed after melatonin administration. Testis width from April to June and stage of spermatogenesis in May and June were greater in the treated animals than in the controls; however, from July onwards the differences between the two groups were no longer significant. Serum concentrations of testosterone remained low (below the detection limit in most cases) in both treated and control animals throughout the study period. Melatonin treatment also affected moulting, which was assessed by changes in the number of growing and mature underfur hairs per bundle and the percentage of bundles with a growing guard hair. The treated animals showed a more rapid shedding of mature underfur hairs and growth of new underfur hairs 6 weeks after melatonin implantation compared with the controls. During the study period, there were significantly more growing underfur hairs per bundle in May to August (4-9 per bundle) and a lower percentage of bundles with a growing guard hair in May and August (38 and $74 \%$, respectively) in the treated animals compared with controls (1-4 per bundle; 79 and 93\%), indicating that melatonin treatment stimulated the initiation of growth of underfur hairs and inhibited that of guard hairs. Although melatonin administration in March slowed testicular regression and maintained an unchanged winter coat in the initial stage, earlier melatonin implantation may delay testicular regression and spring moult more effectively in raccoon dogs.
\end{abstract}

\section{Introduction}

The raccoon dog is a seasonal breeder with a mating period of approximately 6 weeks in February and March. During the mating period, the males are willing to mate and produce mature spermatozoa, while oestrus of the females lasts for only about 4 days, and is followed by a gestation of about 61 days if mating occurs (Valtonen et al., 1977). Male raccoon dogs exhibit a marked seasonal variation in both testicular size and serum concentrations of testosterone, which begin to increase during autumn when daylength is decreasing, reach peak values in the mating season and return to basal values during May to August when days are long (Xiao et al., 1994). Seasonal moulting is also probably controlled by photoperiod. In contrast to some fur-bearing animals, such as mink, ferrets and

*Correspondence.

Received 13 February 1995.

blue foxes, which have two distinct moulting periods (in spring and autumn), raccoon dogs exhibit only one complete annual pelage change, characterized by a heavy spring loss and an intensive autumn regrowth of underfur hairs and a long growth period (spring to autumn) of guard hairs (Blomstedt, 1991; Xiao, 1995).

Seasonality in reproduction and moulting is ultimately controlled by photoperiod, which may exert a regulatory role on the neuroendocrine system via the pineal hormones melatonin in particular (Duby and Travis, 1972; Allain et al., 1981; Martinet et al., 1981; Almeida and Lincoln, 1982). Exogenous melatonin produces profound changes in testicular and moulting cycles. An early testicular recrudescence and autumn moult are induced by melatonin treatment in summer when the animals normally have quiescent testes and a summer coat, whereas testicular regression and spring moult are delayed by melatonin administration during winter when the animals have active testes and a winter coat (mink: Allain et al., Downloaded from Bioscientifica.com at 04/26/2023 07:50:20AM 
1981; Rose et al, 1985; blue fox: Smith et al., 1987a; silver fox: Forsberg et al., 1990). In raccoon dogs, either artificial short day (Men et al., 1990) or melatonin treatment (Blomstedt et al., 1988; Xiao and Blomstedt, 1994) beginning in summer advances the autumn moult and growth of winter fur.

Prolactin secretion in most animals studied shows a marked seasonal variation with high concentrations in spring and early summer, which can be suppressed by a short photoperiod and by treatment with melatonin. This finding indicates that prolactin is probably involved in the control of annual testicular and moulting cycles. Indeed, some studies have demonstrated that prolactin plays a central role in the control of the moulting cycles in mink, sheep and blue foxes (Allain et al., 1981; Martinet et al., 1981, 1984; Rougeot et al., 1984; Smith et al., 1987a, b). In male Syrian hamsters, long-day breeders, there is increasing evidence that prolactin plays an important role in mediating photoperiodic effects on the gonads (for a review, see Steinlechner and Niklowitz, 1992). In rams, there is a relationship between low prolactin concentrations and high FSH concentrations and the maintenance of testicular activity (Langford and Labrie, 1986). However, no fixed relationship has been observed between annual prolactin secretion and the testicular cycle in mink, blue foxes and silver foxes (Martinet et al., 1982; Smith et al., 1985; Forsberg and Madej, 1990; Martinet et al., 1992; DiGregorio et al., 1994).

The raccoon dog, a recently introduced fur animal, is now bred in large numbers in northern and eastern Europe, Russia and Asia. However, knowledge of the roles of photoperiod and melatonin in the reproductive and moulting cycles is limited in this species. The aim of the present study was to investigate the effects of melatonin treatment in the spring on prolactin secretion, testicular activity and moulting cycle in adult male raccoon dogs.

\section{Materials and Methods}

\section{Animals and treatments}

Twelve farmed male raccoon dogs (Nyctereutes procynoides), 1-2 years old and weighing $5.3-6.5 \mathrm{~kg}$, were used in this study which lasted from March to August 1993. The animals were housed outdoors in individual cages with a shelter at the Research Farm for Fur Bearing Animals of the University of Kuopio, Juankoski $\left(63^{\circ} \mathrm{N} ; 28^{\circ} \mathrm{E}\right)$, Finland. The animals were fed with a commercial standard wet diet, and water was given ad libitum. On 29 March, six of the 12 animals received a constant-release implant containing $12 \mathrm{mg}$ melatonin (Wildlife Laboratories, Fort Collins, CO) s.c. over the scapular area. The other six male raccoon dogs served as controls.

\section{Measurement of width of testis and collection of specimens}

Testis width, defined as the largest horizontal width of two testes, was measured through the scrotum using callipers at intervals of 3 weeks from 29 March to 10 August. Samples of blood, testis and skin were taken at the same intervals during the same period. On 29 March, the first sampling date, all the samples had been taken just before the animals were implanted with melatonin. Sampling was performed under sterile conditions and under general anaesthesia with medetomidine hydrochloride $\left(0.1 \mathrm{mg} \mathrm{kg}^{-1}\right.$ i.m., Orion Corporation, Turku).

Blood sampling. The blood samples were collected from the jugular vein between 9:00 and 11:00 h. The serum was separated by centrifugation ( $15 \mathrm{~min}$ at $1000 \mathrm{~g}$ ) and stored at $-20^{\circ} \mathrm{C}$ until assayed.

Testis and skin biopsies. Testes were percutaneously punctured with a 19-gauge needle, avoiding any injury to the epididymis. A $10 \mathrm{ml}$ syringe was used to produce negative pressure and the vacuum was released before withdrawing the needle from the testis. The samples were spread onto object glasses, air-dried and stained with a rapid staining set for blood smears (Hemacolor ${ }^{11}$, Merck, Darmstadt). When differences in testicular size were found, the larger testis was used for biopsies. Skin samples $(6.3 \mathrm{~mm}$ in diameter), taken from the hip with a trephine, were immediately immersed in $10 \%(\mathrm{v} / \mathrm{v})$ neutral formalin.

Castration. One male raccoon dog from the control group and another from the treatment group were hemicastrated on 21 July to determine whether the testicular tissue was damaged by the successive biopsies. Testes were excised under general anaesthesia as described above. Representative samples were taken and fixed in $10 \%(\mathrm{v} / \mathrm{v})$ formalin. Histological sections were made and stained with haematoxylin-eosin, and examined under a light microscope.

\section{Hormone assays}

Melatonin. Melatonin was determined from chloroformextracted serum samples using the radioimmunoassay described by Valtonen et al. (1993). Briefly, serum samples $(0.25$ or $0.5 \mathrm{ml}$ ) and melatonin standards $\left(5.0-100 \mathrm{pg} \mathrm{ml}^{-1}\right)$, as well as low and high melatonin control samples, were extracted in duplicate with $3.0 \mathrm{ml}$ of chloroform. The organic phase was washed with distilled water and dried under a vacuum. The residues were reconstituted in PBS and assayed for melatonin with the antiserum (Stockgrand Ltd, University of Surrey, Guildford) and (O-methyl- $\left[{ }^{3} \mathrm{H}\right]$ ) melatonin as tracer (specific activity $851 \mathrm{mmol}^{-1}$, final dilution 1:30 000, Amersham International plc, Buckinghamshire). Parallelism was assessed between melatonin standards and dilutions of a pool of raccoon dog sera containing high concentrations of melatonin (Fig. 1a). The intra-assay coefficients of variation for two control samples were $12.4 \%\left(8.9 \mathrm{pg} \mathrm{ml}^{-1}\right)$ and $7.1 \%\left(108.5 \mathrm{pg} \mathrm{ml}^{-1}\right)$, and the interassay coefficients of variation $20.6 \%$ and $4.9 \%$, respectively. The sensitivity, defined as the value of two SD below zero standard binding, was $5.0 \mathrm{pg} \mathrm{ml}^{-1}$.

Prolactin. Prolactin was measured with an enzyme immunometric assay designed for canine prolactin (Milenia canine prolactin, Diagnostic Products Corporation, Los Angeles, CA). Parallelism was assessed between canine prolactin standards and dilutions of raccoon dog serum containing a high concentration of prolactin (Fig. 1b). The intraassay coefficient of variation calculated from the precision Downloaded from Bioscientifica.com at 04/26/2023 07:50:20AM 

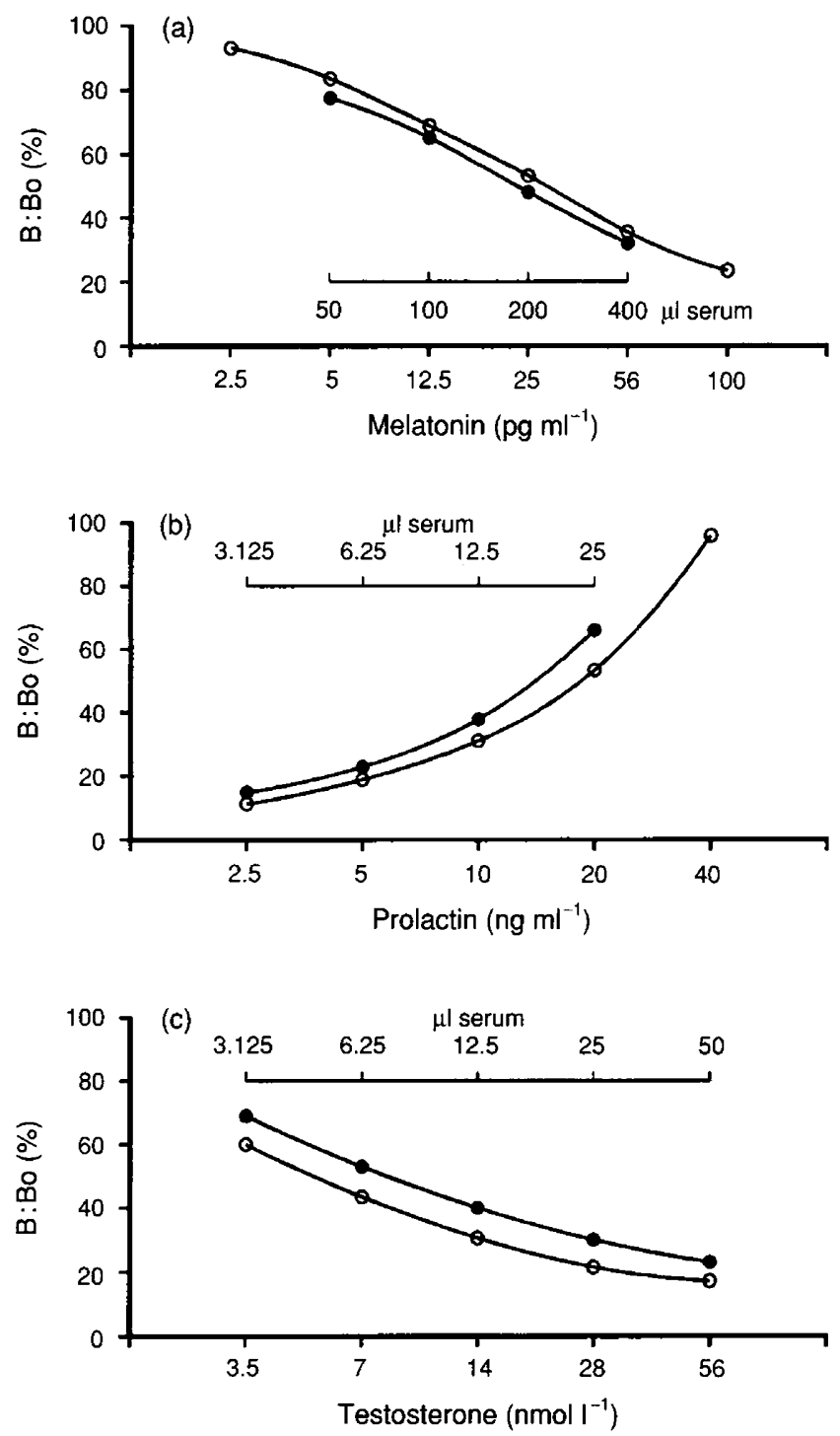

Fig. 1. Standard curves for (a) melatonin, (b) canine prolactin and (c) testosterone, and corresponding dose-response curves of serial dilutions of raccoon dog serum. (o) standard; (•) serum.

profiles of assays was below $10 \%$ for concentrations between 2 and $40 \mu \mathrm{g} \mathrm{I}^{-1}$. The interassay coefficient of variation for a control sample with $4.7 \mu \mathrm{g}$ prolactin $\mathrm{I}^{-1}$ was $8.9 \%$. The detection limit, according to the manufacturer's information, was $0.5 \mu \mathrm{g} \mathrm{I}^{-1}$.

Testosterone. Testosterone was determined using a radioimmunoassay kit (Coat-A-Count, Diagnostic Products Corporation). Parallelism was assessed between testosterone standards and dilutions of raccoon dog serum containing a high concentration of testosterone (Fig. 1c). The intra-assay coefficients of variation for three control samples in four assays were $10.4 \%\left(3.6 \mathrm{nmol} \mathrm{l}^{-1}\right), 5.6 \%\left(22.3 \mathrm{nmol} \mathrm{l}^{-1}\right)$ and $6.0 \%$ $\left(49.6 \mathrm{nmol} \mathrm{I}^{-1}\right)$; the interassay coefficients of variation were $12.4 \%, 5.7 \%$ and $11.2 \%$, respectively. The least detectable amount of testosterone was $0.2 \mathrm{nmol} \mathrm{l}^{-1}$.
Evaluation of spermatogenesis

The score count (Johnsen, 1970) for determining the stage of spermatogenesis was modified and used to evaluate spermatogenesis in the aspirates of testes. The modified criteria of score count, principally based on the most advanced spermatogenetic cells, were as follows: Score 1 : spermatogonia A only; Score 2: no cells further than spermatogonia B; Score 3: no cells further than $\mathrm{L}$ (leptotene) primary spermatocytes; Score 4: no cells further than $Z$ (zygotene) primary spermatocytes; Score 5: no cells further than $P$ (pachytene) primary spermatocytes; Score 6: no cells further than round spermatids; Score 7: no cells further than the small head form of the spermatozoon; Score 8: few mature-phase spermatozoa ( $\leqslant 5$ in each field under $\times 400$ ); and Score 9: many mature-phase spermatozoa ( $>5$ in each field under $\times 400$ ).

The whole sample was usually examined under a light microscope, using a low $(\times 100)$ and then a high $(\times 400)$ magnification. A score was given to the individual biopsies and a mean score count was calculated for both groups. In some cases, particularly during the quiescent phase of the testis, no scores could be given to some biopsies, as no spermatogenic cells were found. However, there were, at most, two such biopsies on each sampling date in each group.

\section{Histological examination of skin}

After fixing the skin samples in formalin for $24 \mathrm{~h}$, they were treated histologically using routine dehydration and paraffin wax techniques. Cross-sections $(8-10 \mu \mathrm{m}$ thick) of skin were cut at the sebaceous gland and stained with haematoxylin and eosin. Each hair bundle in the cross-sections contains a guard hair and may or may not contain underfur hairs. The guard and underfur hairs in each bundle may be mature or growing, or both types may co-exist in the same follicle (guard hair) and the same bundle (underfur hairs). Mature or growing hair was judged by the presence or absence of a hair medulla (Blomstedt, 1989). Mean numbers of mature and growing underfur hairs per bundle for each individual were determined from 9-12 hair bundles randomly selected from the skin section. The percentage of bundles with a growing guard hair, including bundles with both growing and mature guard hair and bundles with only a growing guard hair, was calculated from all the bundles in the section. The best sections, 3-5 in each group, were used on each sampling date for determination of the above parameters.

\section{Statistical analyses}

The SPSS/PC $+{ }^{\mathrm{TM}} \mathrm{V} 3.0$ (SPSS Inc. Chicago, IL) was used for analysis of the data. Analysis of variance for repeated measures was used to determine significant differences within and between treatments. The least significant difference was used for multiple comparisons. The relationship between testis width and score count of spermatogenesis was assessed by linear correlation analysis. All data are presented as means \pm SEM. 


\section{Results}

\section{Hormone concentrations in serum}

Melatonin. In the melatonin-treated animals, the highest serum concentration of melatonin $\left(182 \mathrm{pg} \mathrm{ml}^{-1}\right.$ ) was observed on 19 April, three weeks after melatonin was implanted (Fig. 2b). Thereafter, the concentrations showed a rapid decrease in May and then a gradual decline until August, at which time, a significantly higher concentration $\left(39 \mathrm{pg} \mathrm{ml}^{-1}\right)$ than that of the control was still maintained. Melatonin concentrations in the control animals were low and close to the detection limit throughout the study period.
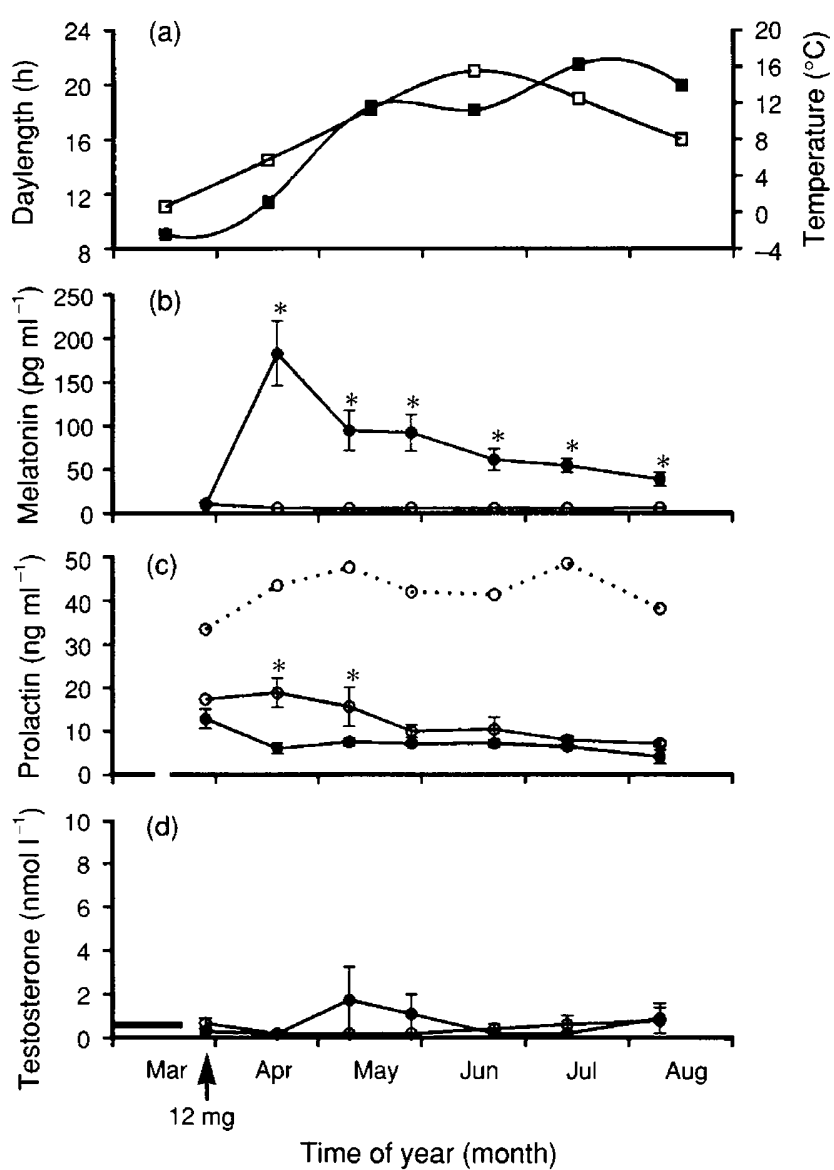

Fig. 2. Variations in (a) monthly means of daylength (*) and temperature (a) and serum concentrations of (b) melatonin, (c) prolactin and (d) testosterone in raccoon dogs treated with melatonin implants ( $\bullet$ ) and untreated controls ( $)$. Means for serum melatonin are calculated from six animals in each group. Means for serum prolactin are calculated from six animals in the treated group, and five animals in April through August and only one animal in March in the control group. Data from a control animal with high serum concentrations of prolactin are shown separately $(\cdots, \cdots)$. Means for serum testosterone are calculated from six animals in each group during April and August, and two in the treated and three in the control group in March. All blood samples were taken between 09:00 and 11:00 h. The arrow and the number under the arrow indicate the date and dose of melatonin administration, respectively. The horizontal bar depicts the duration of the mating season. *Significant difference between the two groups $(P<0.05)$.
Prolactin. There was a marked seasonal variation in serum concentrations of prolactin in the control animals $(P<0.05)$, with the highest concentrations in April and May (17-19 ng $\mathrm{ml}^{-1}$ ) and the lowest concentrations in June to August (7-10 $\mathrm{ng} \mathrm{ml}^{-1}$ ). In contrast, low concentrations (4.1-7.5 ng $\mathrm{ml}^{-1}$ ) were maintained from April until August in the treated animals (Fig. 2c). One of the control animals showed unexpected high concentrations of prolactin throughout the study period; the average was $42.1 \pm 2.0 \mathrm{ng} \mathrm{ml}^{-1}$, over three times that (12.5 $\pm 1.8 \mathrm{ng} \mathrm{ml}^{-1}$ ) of the rest in the group. However, no differences between this animal and others in the group were found in any of the other parameters observed.

Testosterone. Testosterone concentrations in most serum samples were below the detection limit of the assay $(0.2 \mathrm{nmol}$ $\mathrm{I}^{-1}$ ) in both control and treated animals (Fig. 2d). There were no significant variations in the concentrations either within each group during the study period or between the two groups on each sampling date $(P>0.05)$.

\section{Testicular width, biopsies and histology}

By the end of March, the average testicular width was $2.6 \pm 0.1 \mathrm{~cm}$, and the mean score count of spermatogenesis was $8.6 \pm 0.2$ (Fig. 3). Although all types of spermatogenetic cell were found, including mature-phase spermatozoa, in the testicular aspirates of each animal, the testes had already begun to regress. However, testicular regression, as judged by testicular
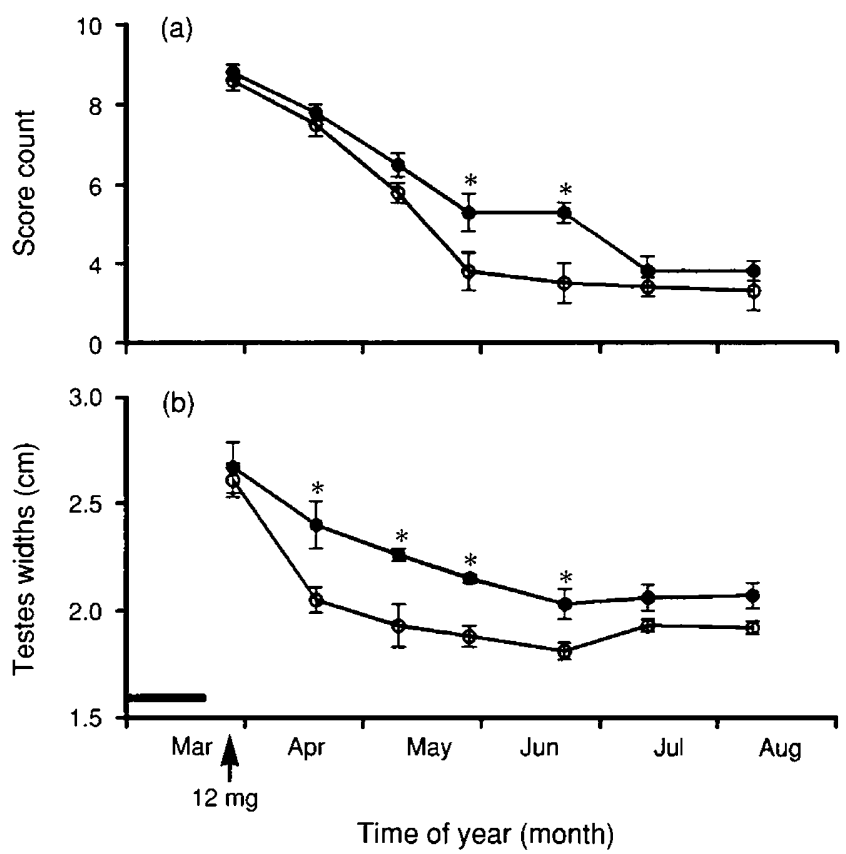

Fig. 3. Variations in (a) score counts of spermatogenesis and (b) testis widths in raccoon dogs treated with melatonin implants $(\bullet)$ and untreated controls (). Means for score counts are calculated from 4-6 animals in each group. Means for testis widths are calculated from 6 animals in each group. The arrow and the number under the arrow indicate the date and dose of melatonin administration, respectively. The horizontal bar indicates the duration of the mating season. * Significant difference between the two groups $(P<0.05)$. 
width and score count of spermatogenesis, was slowed in the treated animals than in the controls. Significant differences in the score counts were observed between the two groups in May and June, when pachytene primary spermatocytes and early spermatids were still present in the treated animals, whereas only zygotene primary spermatocytes were found in the controls (Fig. 3a). Values of testicular widths in April through June were markedly higher in the treated than in the control animals on each sampling date (Fig. 3b). In July and August, there were no clear differences in any of the parameters between the two groups. Nevertheless, zygotene primary spermatocytes, the most advanced spermatogenetic cells, were still observed in both groups.

There was a positive correlation between the score count of spermatogenesis and testis width in the control group $(r=0.71$, $P<0.001)$ and in the melatonin-treated group $(r=0.79$, $P<0.001$ ).

By checking the histological sections from the animals castrated on 21 July, no marked differences were found in cell composition or appearance of tubules between the two groups and no signs of tissue damage or fibrosis caused by the biopsies were found.

\section{Moulting}

Number of underfur hairs per bundle. At the end of March, the animals had a winter coat with only mature underfur hairs in the bundles (Fig. 4a). In April, 3 weeks after melatonin implantation, the number of mature underfur hairs in the control animals was significantly lower than that in the melatonin-treated animals. At that time, the first growing underfur hairs appeared in both treated and control animals (Fig. 4b). During the following 3 weeks, the number of mature underfur hairs decreased, while the number of growing underfur hairs increased in both groups, but the changes were more rapid in the treated animals. Afterwards, the number of mature underfur hairs remained low and there was no significant difference between the two groups on any subsequent sampling date. The number of growing underfur hairs was significantly higher in the treated animals (4-9 per bundle) than in the controls (1-4 bundle) on each sampling date from May to August. However, within the treated animals, there were no clear differences in the number of growing underfur hairs between the sampling dates during June and August $(P>0.05)$. The total number of underfur hairs was also considerably higher in the treated animals than in the control animals during June and August (Fig. 4c). In addition, a marked increase was found in August in the number of growing underfur hairs in the controls and in the number of total underfur hairs in both control and treated animals $(P<0.05)$.

Percentage of bundles with a growing guard hair. In the control animals, the first bundles with a growing guard hair appeared in April. After a rapid increase during May and June, their percentages remained high in July and August, when almost all bundles had a growing guard hair (Fig. 4d). A similar pattern was observed in the treated animals, but the percentages were lower than those in the control animals during the study period.
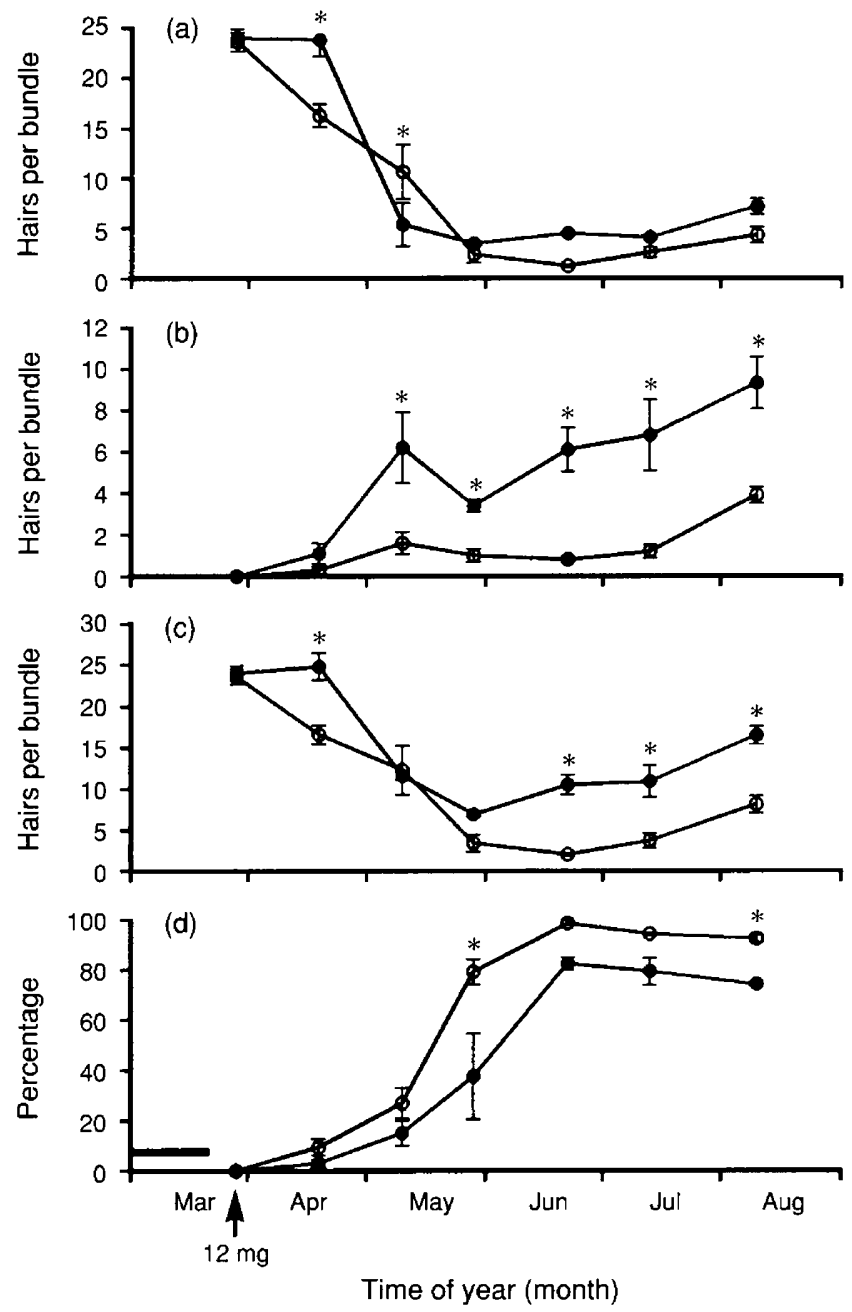

Fig. 4. Variations in numbers of (a) mature, (b) growing and (c) total underfur hairs per bundle, and (d) in percentages of bundles with a growing guard hair in raccoon dogs treated with melatonin implants $(\bullet$ ) and untreated controls ( ). Means for all variables are calculated from 3-5 animals in each group. The arrow and the number under the arrow indicate the date and dose of melatonin administration, respectively. The horizontal bar indicates the duration of the mating season. *Significant difference between two groups $(P<0.05)$.

\section{Discussion}

Melatonin administration to male raccoon dogs in late March clearly affected prolactin secretion, testicular regression and moulting. Testicular regression, as judged by testis width and score count of spermatogenesis, was delayed but not prevented by melatonin implantation. This finding is similar to that found in earlier studies in rams (Lincoln and Ebling, 1985), mink (Allain et al., 1981) and blue foxes (Smith et al., 1987a), in which melatonin treatment in winter leads to prolonged testicular activity, but a stable reproductive condition is not maintained. In silver foxes, the activation of testicular activity by melatonin administration in summer and autumn is followed by a regression, while plasma melatonin concentrations remain high (Forsberg et al., 1990; Forsberg and Madej, 1990). Delayed but not suppressed testicular regression is also found in mink maintained under artificial short photoperiod $(8 \mathrm{~h}$ dark:16 h 
light) beginning from the winter solstice (Martinet et al., 1992). It therefore appears that testes developing under either decreasing photoperiod or melatonin administration finally become refractory to the stimulatory photoperiod or exogenous melatonin. Nevertheless, this experimentally induced refractoriness may not occur under natural conditions. On the basis of the observation that after the winter solstice, testicular regression in mink could be hastened by photoperiods longer than the natural one, Martinet et al. (1992) suggested that photorefractoriness, or inhibition by increasing daylength in late winter, or both, could contribute to the testicular regression under natural conditions. In raccoon dogs, testicular regression, as judged by serum concentrations of testosterone and testis size, begins early in the breeding season (Xiao et al., 1994), suggesting that the photoperiodic signal for testicular regression is perceived by the animal well before the breeding season. Future studies will elucidate whether melatonin given before the breeding season maintains testicular activity for longer.

In male raccoon dogs, as in other short-day breeders, high serum concentrations of prolactin coincided with the onset of testicular regression. However, there seemed to be no fixed relationship between these two parameters. It has been shown that although the annual rise in prolactin secretion is totally suppressed by melatonin administration, testicular regression always occurs, although it is delayed (mink: Allain et al., 1981; blue fox: Smith et al., 1987a; silver fox: Forsberg and Madej, 1990). Studies in rams, mink and blue foxes have also demonstrated that seasonal variations in concentrations of prolactin in blood are not affected by castration, suggesting that prolactin secretion is independent of testicular secretory feedback mechanisms (Ravault et al., 1977; Martinet et al., 1982; Smith et al., 1985). Moreover, artificially increased prolactin concentrations during autumn have no effect on testicular development in mink (DiGregorio et al., 1994). Further evidence for the dissociation between prolactin secretion and testicular cycles was reported by Martinet et al. (1992), who demonstrated that prolactin secretion exhibits an endogenous circannual rhythm, while the testicular activity cycle relies on annual changes in daylength.

Despite the slowed testicular regression, in the present study, serum concentrations of testosterone in the melatonintreated animals remained as low as those of the control animals In blue foxes, delayed testicular regression and increased FSH secretion are induced by melatonin implantation, but plasma testosterone and $\mathrm{LH}$ concentrations are unaffected (Smith et al., 1987a; Mondain-Monval et al., 1988). Smith et al. (1987b) reported that, in blue foxes, testicular regression is delayed by bromocriptine administration but plasma testosterone concentrations remained unchanged. These results imply that FSH, rather than $\mathrm{LH}$ and testosterone, plays a role in the maintenance of testicular activity after the mating season.

In this study, there was no histological evidence that testicular biopsies influenced testicular development or regression. This finding is in agreement with earlier studies in which repeated testicular biopsies were used (Martin and Richmond, 1972; Smith ef al., 1987a).

Melatonin implantation in mid-March in mink (Allain et al., 1981) or in February-March in blue foxes (Smith et al., 1987a), when animals have a winter coat, delays the spring moult until July, whereas implantation in late April in mink (Allain ef al., 1981), when the spring moult has begun, induces a winter coat in August after a long period of moulting. In the present study, exogenous melatonin administered in late March stimulated the growth of underfur hairs, although the winter coat was maintained during the first 3 weeks. However, the insignificant changes in the number of growing underfur hairs from June to August, and the low hair density (16 per bundle at the end of the study in August), indicate that a normal winter coat would not form in the melatonin-treated raccoon dogs. It appears that, in late March, some of the hair follicles were not yet sensitive to the hormone changes induced by exogenous melatonin to grow new hairs and later, when they became sensitive, they were not activated owing to the decreasing melatonin concentrations. Thus the timing of melatonin administration in spring seems to be critical for its effect on the fur cycle. If melatonin had been implanted earlier than in the present study, the spring moult would have been delayed for longer, whereas if implanted later, a winter coat might have been formed. Progression and timing of the spring moulting, which varies among species (Maurel et al., 1986), should be considered when melatonin is administered.

In contrast to the stimulatory effect on the growth of underfur hairs, melatonin administration inhibited the growth of guard hairs. In the raccoon dogs under natural conditions, guard hairs moult once a year, and new guard hairs develop in spring and early summer when daylength increases, while winter underfur hairs develop in autumn when daylength decreases (Xiao, 1995). Differential photoperiod-controlled moulting cycles are therefore suggested for underfur hairs and guard hairs of raccoon dogs. It seems that in raccoon dogs, initiation of the growth of guard hairs, which will comprise the winter coat, is controlled by the same mechanism by which growth of summer coat is initiated in mink.

Mink display a spring moult and an autumn moult, associated with an increase and decrease in plasma concentrations of prolactin, respectively. The spring moult and growth of the summer coat can be induced by prolactin injections and delayed by melatonin administration, which simultaneously suppresses prolactin secretion (Allain et al., 1981; Martinet et al., 1981). In the present study, growth of some guard hairs was prevented probably by suppression of prolactin secretion by melatonin, which, on the contrary, might synchronously contribute to the growth of underfur hairs. However, the regulatory mechanism of the activation of hair follicles is not clear. The possibility of regulators other than prolactin with physiological significance in the control of seasonal moulting cannot be discounted (Rose and Sterner, 1992).

No abnormality in the parameters for moulting and testicular development was found in the one control animal that had high serum concentrations of prolactin during the study. This animal showed a clear decrease in serum prolactin in September as did other control animals, although the prolactin concentration of this animal was higher than that of the others (Y. Xiao, M. Forsberg, J. T. Laitinen and M. Valtonen, unpublished data). This finding suggests that, if prolactin is involved in the moulting and testicular cycles, its seasonal rhythm in blood concentration is more important than its actual concentration in the blood. 
Normal semen can be produced by melatonin-treated silver foxes in the advanced breeding season (Forsberg et al., 1990) and by melatonin-treated blue foxes in the prolonged breeding season (Smith et al., 1987a). A significant practical application for melatonin treatment in late winter or spring in male raccoon dogs is that males with active testes maintained by melatonin administration could offer normal fertile semen to females entering oestrus late in the breeding season, when most of the males have poor quality semen and weak libido. These males could have fairly high-quality winter coats after the breeding season.

In conclusion, melatonin administration to male raccoon dogs in late March maintained high concentrations of melatonin in blood and slowed testicular regression, as demonstrated by measurements of testis widths and score counts of spermatogenesis. In addition, melatonin treatment showed a stimulatory effect on the initiation of growth of underfur hairs and an inhibitory effect on the growth of guard hairs. However, further studies should investigate whether an earlier melatonin administration would effectively delay testicular regression and spring moult.

The authors thank R. Savolainen and E. Reinikainen for excellent technical assistance during the experiments and $S$. Kukkonen and $\AA$. Karlsson for hormone assays. Y. Xiao was financially supported by the Centre for International Mobility of Finland.

\section{References}

Allain D, Martinet L and Rougeot J (1981) Effect of melatonin implants on changes in the coat, plasma prolactin level and testis cycle in the mink (Mustela vison). In Photoperiodism and Reproduction pp 263-271 Eds R Ortavant, J Pelletier and JP Ravault. INRA, Nouzilly

Almeida OFX and Lincoln GA (1982) Photoperiodic regulation of reproductive activity in the ram: evidence for the involvement of circadian rhythms in melatonin and prolactin secretion Biology of Reproduction 27 1062-1075

Blomstedt L (1989) Histological determination of different stages of pelage development. Fur growth of mink Acta Agriculturae Scandinavica 39 91-99

Blomstedt L (1991) Raccoon dog: the structure and growth phases of the pelt Scientifur 15 330-331

Blomstedt L, Valtonen M, Pölönen I and Jalkanen L (1988) Investigation on the use of melatonin Finsk Pälstridskrift 12 158-162

DiGregorio GB, González Reyna A and Murphy BD (1994) Roles of melatonin and prolactin in testicular crudescence in mink (Mustela vison) Journal of Reproduction and Fertility 102 1-5

Duby RT and Travis HF (1972) Photoperiodic control of fur growth and reproduction in the mink (Mustela vison) Journal of Experimental Zoology $\mathbf{1 8 2}$ $217-226$

Forsberg M and Madej A (1990) Effects of melatonin implants on plasma concentrations of testosterone, thyroxine and prolactin in the male silver fox (Vulpes vulpes) Journal of Reproduction and Fertility 89 351-358

Forsberg M, Fougner JA, Hofmo PO and Einarsson EJ (1990) Effect of melatonin implants on reproduction in the male silver fox (Vulpes vulpes) journal of Reproduction and Fertility 88 383-388

Johnsen SG (1970) Testicular biopsy score count - a method for registration of spermatogenesis in human testes: normal values and results in 335 hypogonadal males Hormones $12-25$

Langford GA and Labrie F (1986) Photoperiod entrainment of different LH, FSH and prolactin cycles in rams in relation to testicular function Biology of Reproduction 34 Stupplement 157 Abstract 16

Lincoln GA and Ebling FJP (1985) Effect of constant-release implants of melatonin on seasonal cycles in reproduction, prolactin secretion and moulting in rams Journal of Reproduction and Fertility $73241-253$
Martin KY and Richmond ME (1972) A method for repeated sampling of testis tissue from small mammals Laboratory Animal Science 22 541-545

Martinet L, Meurnier M and Allain D (1981) Control of delayed implantation and onset of spring moult in the mink (Mustela vison) by daylight ratio, prolactin and melatonin. In Photoperiodism and Reproduction pp 253-261 Eds R Ortavant, J Pelletier and JP Ravault. INRA, Nouzilly

Martinet L, Ravault JP and Meurnier M (1982) Seasonal variations in mink (Mustela vison) plasma prolactin, measured by heterologous radioimmunoassay General and Comparative Endocrinology 48 71-75

Martinet L, Allain D and Weiner C (1984) Role of prolactin in the photoperiodic control of moulting in the mink (Mustela vison) Journal of Endocrinology 103 9-15

Martinet L, Mondain-Monval M and Monnerie R (1992) Endogenous circannual rhythms and photorefractoriness of testis activity, moult and prolactin concentrations in mink (Mustela vison) Journal of Reproduction and Fertility 95 325-338

Maurel D, Coutant C, Boissin-Agasse L and Boissin J (1986) Seasonal moulting patterns in three fur bearing mammals: the European badger (Meles meles $L$.), the red fox (Vulpes vulpes L.), and the mink (Mustela vison). A morphological and histological study Canadian Journal of Zoology 64 1757-1764

Men T, Xiao Y, Song J and Liu J (1990) The effect of shortened daily photoperiod on winter coat growth in raccoon dogs Chinese Journal of Zoology 3 38-40

Mondain-Monval M, Smith AJ, Simon P, Møller OM, Scholler R and McNeilly AS (1988) Effect of melatonin implantation on the seasonal variation of FSH secretion in the male blue fox (Alopex lagopus) Journal of Reproduction and Fertility 83 345-354

Ravault JP, Bartke A and Caraty A (1977) Plasma prolactin levels in castrated testosterone-treated lambs Journal of Endocrinology 72 235-236

Rose J and Sterner M (1992) The role of the adrenal glands in regulating onset of winter fur growth in mink (Mustela vison) Journal of Experimental Zoology $262469-473$

Rose J, Stormshak F, Oldfield J and Adair J (1985) The effects of photoperiod and melatonin on serum prolactin levels of mink during the autumn molt Journal of Pineal Research 2 13-19

Rougeot J, Allain D and Martinet L (1984) Photoperiodic and hormonal control of seasonal coat changes in mammals with special reference to sheep and mink Acta Zoologica Fennica 171 13-1.8

Smith AJ, Mondain-Monval M, Moller OM, Scholler R and Hansson V (1985) Seasonal variations of $\mathrm{LH}$, prolactin, androstenedione, testosterone and testicular FSH binding in the male blue fox (Alopex lagopus) Journal of Reproduction and Fertility $\mathbf{7 4}$ 449-458

Smith AJ, Mondain-Monval M, Andersen Berg K, Simon P, Forsberg M, Clausen OPF, Hansen T, Moller OM and Scholler R (1987a) Effects of melatonin implantation on spermatogenesis, the moulting cycle and plasma concentrations of melatonin, LH, prolactin and testosterone in the male blue fox (Alopex lagopus) Journal of Reproduction and Fertility 79 379-390

Smith AJ, Mondain-Monval M, Simon P, Andersen Berg K, Clausen OPF, Hofmo PO and Scholler R (1987b) Preliminary studies of the effects of bromocriptine on testicular regression and the spring moult in a seasonal breeder, the male blue fox (Alopex lagopus) Journal of Reproduction and Fertility 81 517-524

Steinlechner S and Niklowitz P (1992) Impact of photoperiod and melatonin on reproduction in small mammals Animal Reproductive Science 30 1-28

Valtonen MH, Rajakoski EJ and Mäkelä JI (1977) Reproductive features in the female raccoon dog (Nyctereutes procyonoides) Journal of Reproduction and Fertility 51 517-518

Valtonen M, Laitinen JT and Eriksson L (1993) Renal melatonin excretion in sheep is enhanced by water diuresis Journal of Endocrinology 138 445-450

Xiao Y Seasonal moulting in adult male raccoon dog Acta Agriculturae Scandinavica in press

Xiao $Y$ and Blomstedt $L$ (1994) Effect of melatonin on winter fur development in adult male raccoon dogs. In Proceedings of the Interdisciplinary Symposium on Fur and Leather Technology pp 40-49 Eds T Korpiharju, P Kujala, M Marjoniemi and E Mäntysalo. Tampere University of Technology, Tampere

Xiao Y, Jiao S, Tong Y, Song J and Wang G (1994) Seasonal changes in testicular size and serum testosterone levels and the relationships between serum testosterone concentrations and reproductive performance in male raccoon dogs Scientifur 18 39-43 